\title{
Persuasive Technologies for Sustainable Mobility: State of the Art and Emerging Trends
}

\author{
Evangelia Anagnostopoulou ${ }^{1}$, Efthimios Bothos ${ }^{1, *}$, Babis Magoutas ${ }^{1}$, Johann Schrammel ${ }^{2}$ and \\ Gregoris Mentzas ${ }^{1}$ \\ 1 Institute of Communication and Computer Systems (ICCS), National Technical University of \\ Athens (NTUA), Athens 15773, Greece; eanagn@mail.ntua.gr (E.A.); elbabmag@mail.ntua.gr (B.M.); \\ gmentzas@mail.ntua.gr (G.M.) \\ 2 Austrian Institute of Technology (AIT), Vienna 1210, Austria; Johann.Schrammel@ait.ac.at \\ * Correspondence: mpthim@mail.ntua.gr; Tel.: +30-694-5141508
}

Received: 30 April 2018; Accepted: 14 June 2018; Published: 22 June 2018

\begin{abstract}
In recent years, persuasive interventions for inducing sustainable mobility behaviours have become an active research field. This review paper systematically analyses existing approaches and prototype systems as well as field studies and describes and classifies the persuasive strategies used for changing behaviours in the domain of mobility and transport. We provide a review of 44 papers on persuasive technology for sustainable transportation aiming to (i) answer important questions regarding the effectiveness of persuasive technology for changing mobility behaviours, (ii) summarize and highlight trends in the technology design, research methods, strategies and theories, (iii) uncover limitations of existing approaches and applications, and (iv) suggest directions for future research.
\end{abstract}

Keywords: persuasive technologies; sustainable mobility; behavioral change; literature review

\section{Introduction}

Transport systems have significant impacts on the environment, accounting for about $25 \%$ of world energy consumption and carbon dioxide emissions [1]. Current transportation practices are not sustainable, as recent reports show that the greenhouse gas (GHG) emissions from transport are increasing at a faster rate than any other energy using sector, especially in urban environments [2]. Modern cities suffer from over-exploitation of land resources, increased urbanisation, and mobility solutions that are highly dependent on private vehicles. This has resulted in highly congested urban environments and conditions detrimental to the quality of life of local inhabitants with adverse effects on public health and the environment.

In order to respond to these unsustainable conditions, a broad range of strategies is required, such as improving vehicle efficiency, lowering the carbon content of fuels, and reducing vehicle miles of travel. Moreover, increasing travellers' awareness of the environmental impact of travel mode choices and changing the citizen's behaviour toward adopting transportation habits that rely more on the use of public transportation, bicycles and walking and less on private cars, can provide the means to reduce GHG emissions in the short term, and mitigate the effects on the environment. Other positive effects of changed transportation habits include less local air pollution and smog, as well as more healthy lifestyles with increased exercise and less obesity [3].

In this context, persuasive technologies, tailored for and integrated in applications that support mobility (e.g., route planners), can affect travellers' decisions and guide them toward selecting routes that are environmentally friendly. Persuasive technology is broadly defined as technology that is designed to change attitudes or behaviours of the users through persuasion and social influence but not through coercion [4]. Persuasive systems addressing behaviour change in the context of personal 
mobility is an active area of research, and numerous systems and implementations exist, aiming to motivate users toward making more eco-friendly choices.

Many approaches utilizing different strategies such as behaviour feedback, social comparison, goal-setting, gamification, personalized suggestions, and challenges have been used so far, and new ones are continuously being developed. Similar to the diversity of approaches, the implementation details (e.g., mobile trip planner apps versus web-based systems) are also very divergent. Last but not least, the transportation context, especially the available infrastructure, possible trip alternatives, and costs associated with the different transportation modes, are defined by the targeted area and can vary substantially. Due to this kaleidoscope of influences and variables, both researchers and practitioners may find it difficult to extract the main findings relevant for their own project or research interests.

In this paper, we review persuasive system implementations and related pilot studies, aiming to systematize available research results and provide a framework for understanding and interpreting approaches for persuasion in the context of personal mobility. Our review examined papers of the last 15 years, from 2003 to early 2018, and focused on the intersection of the following domains: Persuasive Technologies, Personal and Multi-Modal Mobility and Transport Behavioural Change. This means that we do not include in our analysis related work from transport research that deals with incentives or policies for behavioural change without the use of technology. We focus on persuasive technology that supports travellers to select environmentally friendly modes (i.e., switch from car to public transport, bicycle and walking) and to continue using such modes. Note that we do not include related work that is not grounded on persuasive technologies and for example makes use of incentives or other types of means for nudging users toward sustainable transportation without employing persuasive technologies. The focus of this review is depicted in Figure 1.

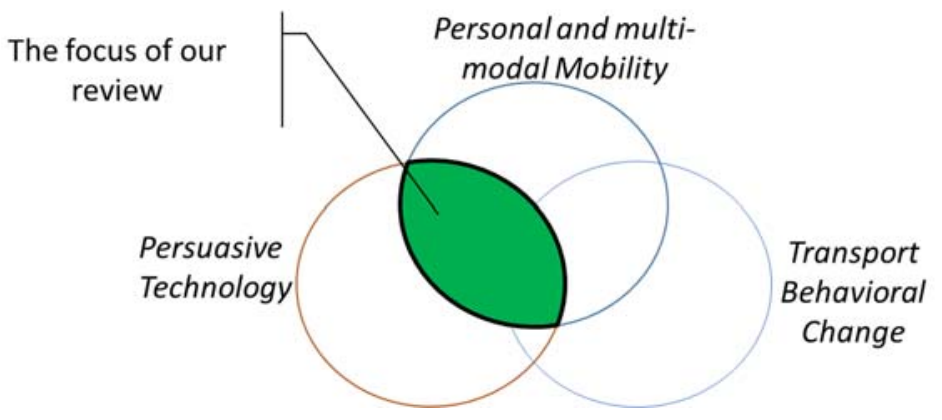

Figure 1. The focus of this review. Our work is positioned at the intersection of Persuasive Technologies, Personal and Multi-Modal Mobility and Transport Behavioural Change.

Our goals in this review paper are to (i) provide an overview of the effectiveness of persuasive technology for sustainable mobility; (ii) list and highlight emerging trends with respect to the technological interventions, research methods, target mobility behaviour, use of persuasive strategies and behaviour change theories-this allows us to provide guidance and set the roadmap for a future research agenda; (iii) summarize shortcomings of existing persuasive technology interventions for sustainable mobility; and (iv) provide directions for future research. The paper is organized as follows. Section 2 presents the methodology followed for the review analysis. Section 3 describes the results our analysis, including the analysis of identified persuasive systems and related pilot studies. Section 4 discusses the findings of our review and provides a research agenda for future work. Finally, Section 5 concludes the paper with our final remarks and next steps.

\section{Methodology}

We used the methodology introduced in [5] that provides rigorous and well-defined guidelines for performing literature reviews. Firstly, we determined the need for an elaborate review in the field of persuasive technologies for sustainable mobility. The increasing number of papers on persuasive 
technologies for sustainable mobility is ample evidence that it has been an important issue in the last years (we have identified 44 relevant papers). Identifying appropriate persuasive strategies and system designs to induce sustainable behaviours in transportation is needed for future studies in this field. Hence, there is a need to conduct a systematic review of the results from past studies that used different strategies and systems to persuade users to make more sustainable choices.

In order to identify the relevant studies for the review, we chose bibliographic databases that cover the majority of journals and conference papers published in the field of persuasive technologies and computer science in general. We selected the following bibliographic databases as relevant: Google Scholar, ACM, IEEE, ScienceDirect, SpringerLink, Emerald, Ebsco, Web of Science, and Proquest. To retrieve the relevant papers, we carried out searches in these databases with the following combinations of keywords: "persuasion", "persuasive technologies", "sustainable mobility", and "behavioural change". The selection of these databases ensured a good coverage of technological mobility interventions across various fields including Human-Computer Interaction (HCI), transportation and mobility information systems, intelligent transportation systems, and other related research fields. Finally, we examined the reference lists of the included papers in order to identify additional relevant work. The total number of papers retrieved through the above method was 904. We filtered papers based on their relevancy, first by examining their title. We excluded 682 papers (for example, a paper entitled "Our place or mine? Exploration into collectivism-focused persuasive technology design" was not included in the review as it is clearly out our scope), and for the remaining, we examined their abstract, introduction, and conclusions (for example, a paper entitled "Celerometer and idling reminder: persuasive technology for school bus eco-driving" was not considered as after checking the abstract and introduction we identified that the focus was only on eco-driving which is out of the scope of our paper). Our aim was to select the papers that employ persuasive technologies and/or implement a persuasive application for sustainable mobility using one or more strategies and/or present results from pilot cases. Considering the above restrictions, we selected 44 papers for final review. The process described above is depicted in Figure 2.

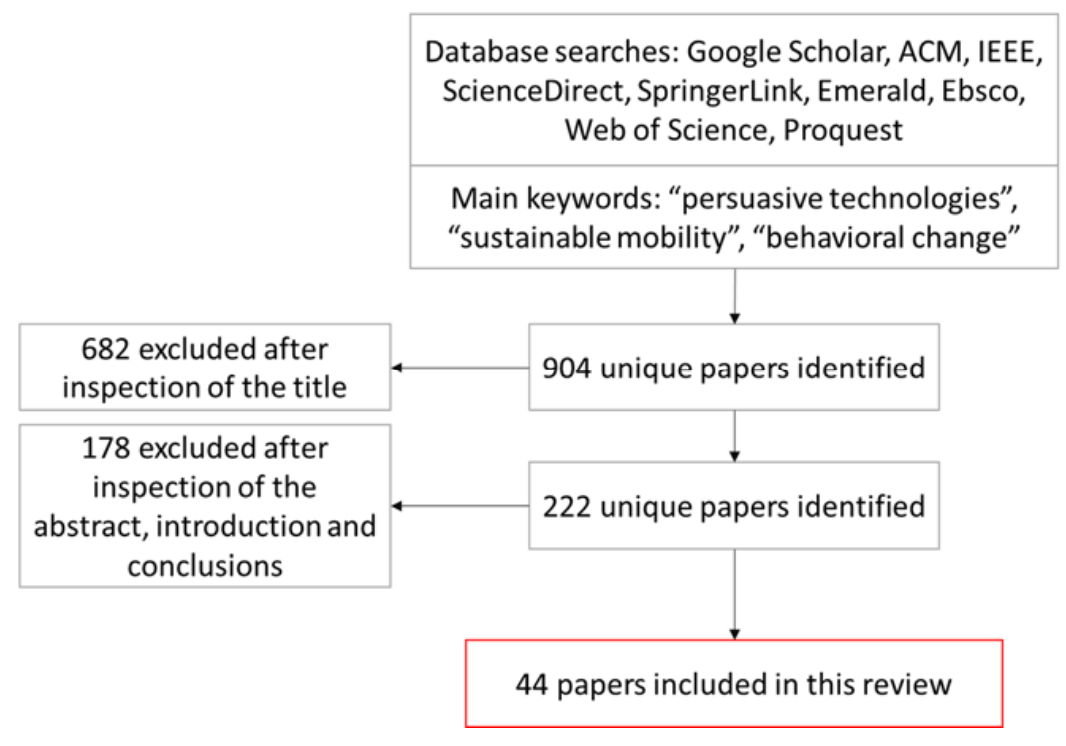

Figure 2. Overview of the paper identification process. We include 44 papers in this review out of 904 initially identified.

The process of engaging in the detailed review of the identified 44 papers involved the development of a coding scheme consisting of 11 analysis dimensions that we used to document the characteristics of each paper (see Table 1). The analysis of the paper characteristics using the coding scheme of Table 1 led to the results presented in Section 3. 
Table 1. Persuasive technology for sustainable mobility analysis coding scheme and dimensions.

\begin{tabular}{|c|c|c|c|}
\hline$\#$ & $\begin{array}{l}\text { Topic of Analysed } \\
\text { Papers }\end{array}$ & $\begin{array}{l}\text { Analysis Dimensions } \\
\text { Considered }\end{array}$ & Identified Classifications \\
\hline 1 & & Descriptive Information & Year and country \\
\hline 2 & $\begin{array}{l}\text { Design, System, } \\
\text { Evaluation }\end{array}$ & $\begin{array}{l}\text { Persuasive Strategies } \\
\text { Integrated }\end{array}$ & $\begin{array}{l}\text { Persuasive strategies used in the design of the } \\
\text { system (see Table } 2 \text { for an overview of the } \\
\text { persuasive strategies which are used in the } \\
\text { reviewed papers). }\end{array}$ \\
\hline 3 & 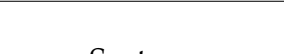 & Type of Application & Route planning, game, feedback. \\
\hline 4 & System & Technology & Web app, mobile app, both, design only. \\
\hline 5 & & Country of Evaluation & Country where the study/pilot was conducted. \\
\hline 6 & & Duration of Evaluation & Hours, Days, Weeks, Months, Years. \\
\hline 7 & Evaluation & Number of Participants & $\begin{array}{l}\text { Number of participants involved in the } \\
\text { evaluation. }\end{array}$ \\
\hline 9 & & Evaluation Method & Quantitative, Qualitative, Mixed. \\
\hline 10 & & Evaluation Target & Behaviour, Attitude, System/approach. \\
\hline 11 & & Evaluation Results & Successful, partially successful, not successful. \\
\hline
\end{tabular}

The process for defining these dimensions was iterative and new dimensions were added as we progressed with our review. The first two dimensions (Descriptive Information and Persuasive Strategies Integrated) are applicable to all papers. Dimensions "Type of Application" and "Technology" are applicable only to papers that focus on the description of a persuasive system, while dimensions 5-11 are applicable to papers dealing with the evaluation of a persuasive technology approach. It should be noted that the topics a paper covers are not mutually exclusive, meaning that a paper may be describing both a persuasive system and its evaluation. Figure 3 provides an overview of our review and depicts the number of papers per analysis dimension along with the applicable attributes.

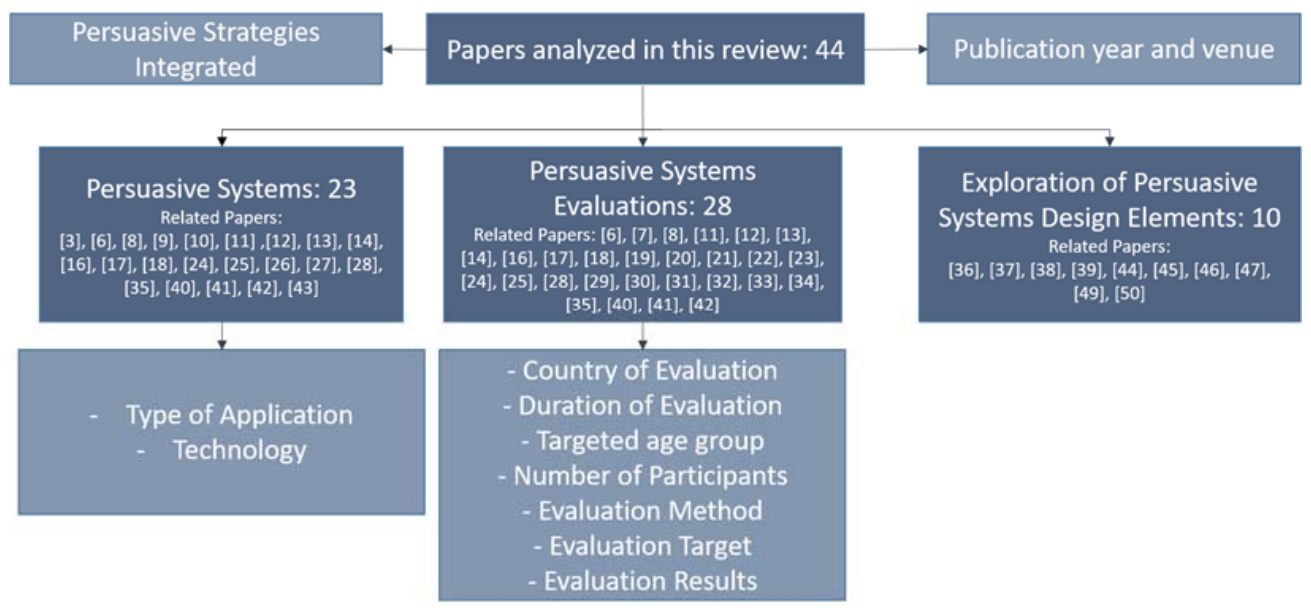

Figure 3. The map of our review. Paper analysis dimensions and applicable attributes. Note that the numbers in the three middle boxes does not add up to 44 , since there are papers which are in more than one categories.

\section{Results}

The analysis of existing persuasive systems in the domain of sustainable mobility led to some interesting results. In the following we present our findings based on the analysis dimensions reported in Table 1. 


\subsection{Persuasive Technology in Mobility by Year}

With respect to the number of papers per year (see Figure 4), we observe a trend of an increasing number of related published papers, especially after 2010. In the figure, we observe that 2016 has been the year with the most papers being published. Note that our latest search for related papers was conducted in the middle of 2018.

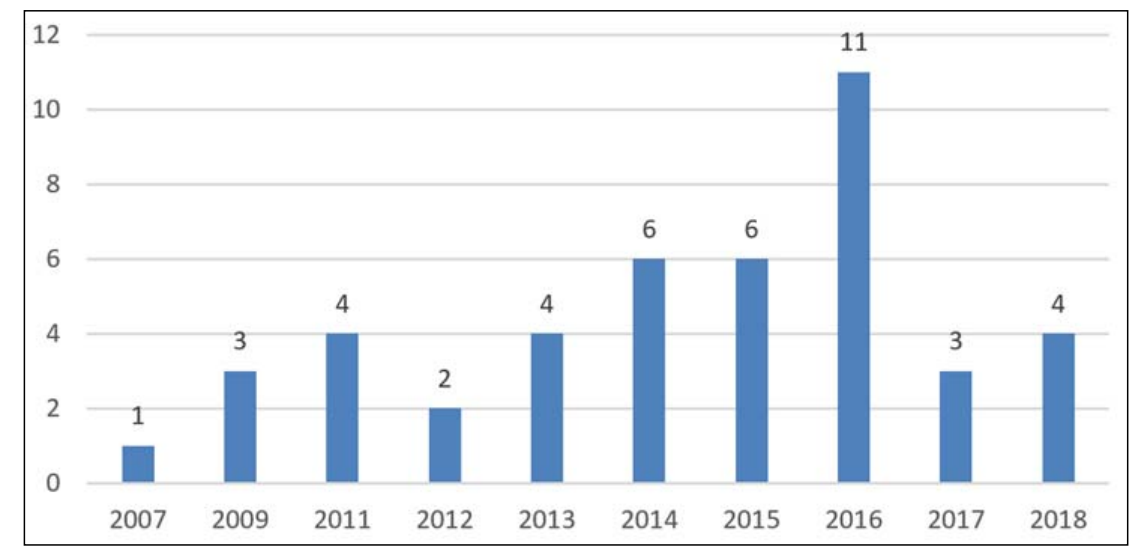

Figure 4. Published papers related to persuasive technologies for sustainable mobility by year.

\subsection{Employed Persuasive Strategies}

The reviewed persuasive systems and studies incorporate one or more persuasive strategies in order to motivate behavioural change and support sustainable transportation decisions. During the review, we identified a set of 11 strategies that are commonly used. These strategies are summarized in Table 2 together with their definition. The identified strategies will be used for the purposes of our analysis in the remainder of this paper.

We observe that self-monitoring is the most frequently used persuasive strategy and typically takes the form of visual feedback. The information most commonly being visualized is the $\mathrm{CO}_{2}$ emissions caused by the users' trips ([6-11]). Certain approaches provide visualizations of the cost and burned calories $([8,10,12])$ calculated from users' mobility patterns. The assumption is that when one switches to more environmentally friendly and active transport modes (e.g., from car to public transport or bicycle) the cost of mobility is reduced, and users burn more calories.

Two forms of feedback are commonly used. Visual designs aim to communicate in a simple and user-friendly manner aggregate statistics and take the form of cognitive representations of concepts that change based on users' activities. These concepts commonly rely on trees that grow as users adopt more sustainable habits $([7,11])$, while in [7], an additional concept of a growing iceberg was used, which provides conceptual correlations to climate change. The second form of feedback refers to charts (including bar and pie charts) presenting detailed statistics of the users' behaviour ([8,10-12]). Visual feedback is typically combined with and supports other persuasive strategies, e.g., support for goal-setting and challenges, social comparison, inclusion of gamification and rewards (playful aspects), or personalized suggestions/messages.

Social aspects take the form of comparing the individual user performance to that of her/his peers (commonly other users who participate in the studies). The comparison can be provided by the system through visual feedback that provides analytics and information of user's performance compared to others, or through social recognition with leaderboards that rank users according to their performance $([13,14])$. Additionally, it can be supported with functionalities that allow users to post their performance in social networks [3]. Rewards are commonly given to users in the form of points when they opt for sustainable transportation modes $([11,13,14])$. Persuasive messages are commonly text based, whereas in [10] an approach that combines text with images is proposed. 
Table 2. Identified persuasive strategies in urban mobility applications for behavioural change and the mapping of these strategies to the reviewed papers.

\begin{tabular}{|c|c|c|}
\hline $\begin{array}{l}\text { Persuasive } \\
\text { Strategy }\end{array}$ & Description (Adopted from [15] & $\begin{array}{c}\text { Frequency of } \\
\text { Identified Studies }\end{array}$ \\
\hline $\begin{array}{l}\text { Challenges \& } \\
\text { Goal Setting }\end{array}$ & $\begin{array}{l}\text { Offering challenges and setting goals that incentivise the user to show an intended } \\
\text { behaviour in a self-competitive context through a comparison of the present and a } \\
\text { desirable future situation. } \\
\text { Related Papers: }[3,9,11,13,16-23]\end{array}$ & $29 \%$ \\
\hline $\begin{array}{l}\text { Self-monitoring } \\
\text { and Feedback }\end{array}$ & $\begin{array}{l}\text { Applying computing technology to eliminate the tedium of tracking performance } \\
\text { or status helps people to achieve predetermined goals or outcomes. } \\
\text { Related Papers: }[6-13,20,24-34]\end{array}$ & $45 \%$ \\
\hline Tailoring & $\begin{array}{l}\text { Information provided by computing technology will be more persuasive if it is } \\
\text { tailored to the individual's needs, interests, personality, usage context, or other } \\
\text { factors relevant to the individual. } \\
\text { Related Papers: }[13,14,16,21,23,32,35-39]\end{array}$ & $27 \%$ \\
\hline $\begin{array}{c}\text { Social } \\
\text { comparison }\end{array}$ & $\begin{array}{l}\text { System users will have a greater motivation to perform the target behaviour if they } \\
\text { can compare their performance with the performance of others. } \\
\text { Related Papers: }[3,8,10-13,16,20,21,25,28,30,32,35,40,41]\end{array}$ & $38 \%$ \\
\hline $\begin{array}{l}\text { Gamification \& } \\
\text { Rewards }\end{array}$ & $\begin{array}{l}\text { To (virtually) reward target behaviours influences people to perform the target } \\
\text { behaviour more frequently and effectively. } \\
\text { Related Papers: }[7,8,10,11,13,14,17,18,22,24,28,30,33,36,37,40-44]\end{array}$ & $45 \%$ \\
\hline Suggestion & $\begin{array}{l}\text { Suggestion technologies are premised on the idea of intervening at the "Right } \\
\text { Time". People feel more motivated to perform some behaviours at certain times } \\
\text { over others, so suggestion technologies are designed to identify these times and } \\
\text { then remind users to perform the behaviours. } \\
\text { Related Papers: }[10,23,28,35]\end{array}$ & $9 \%$ \\
\hline Framing & $\begin{array}{l}\text { Framing is a way of presenting a message in such a way that listeners see it one } \\
\text { way as opposed to another. } \\
\text { Related Papers: [45-47] }\end{array}$ & $4 \%$ \\
\hline Reduction & $\begin{array}{l}\text { Reduction technologies make a complex task simpler, usually by eliminating some } \\
\text { of the steps of a sequence required to achieve a certain goal. } \\
\text { Related Papers: }[10,23]\end{array}$ & $4 \%$ \\
\hline Tunnelling & $\begin{array}{l}\text { Tunneling technologies are designed to reduce "uncertainty", by leading users } \\
\text { through a predetermined sequence of actions or events, step by step, to encourage } \\
\text { certain behaviors. } \\
\text { Related Papers: }[10,23]\end{array}$ & $4 \%$ \\
\hline Simulation & $\begin{array}{l}\text { Systems that provide simulations can persuade by enabling users to observe } \\
\text { immediately the link between cause and effect. } \\
\text { Related Papers: }[10,23]\end{array}$ & $4 \%$ \\
\hline Cooperation & $\begin{array}{l}\text { Systems that motivate users to adopt a target attitude or behavior by leveraging } \\
\text { human beings' natural drive to cooperate. } \\
\text { Related Papers: [25] }\end{array}$ & $2 \%$ \\
\hline
\end{tabular}

\subsection{Persuasive Systems for Sustainable Mobility}

Table 3 presents the 23 persuasive systems we identified in the domain of sustainable mobility. The table provides information regarding the type of the system (whether it is a web or mobile app or both) as well as the persuasive strategies which have been implemented. In the following, we provide a short description of each of the systems we identified.

One of the first attempts is TRIPZOOM [3], which aims to optimize mobility by supporting users to gain insights on their mobility behaviour. The app tracks users' mobility patterns, allows them to zoom in on trip details, including costs, emissions, and impact on health, and provides rewards that incentivize users to save $\mathrm{CO}_{2}$ emissions. Moreover, it supports social comparisons by offering users functionalities to share achievements in social networks such as such as Facebook and Twitter.

The PerCues mobile app [6] aims to persuade people to use public transportation instead of their car in order to reduce emissions. The approach is based on displaying personalized bus and pollution information, such as the departure time of the next bus and the decrease in emissions achieved by 
taking the bus instead of the car. Users can also see the impact of the actions of other users on the environmental pollution.

The UbiGreen app [7] encourages greener alternatives, including carpooling, public transport and pedestrian modalities by providing visual feedback in the form of adapting the background graphics of the smartphone when users reduce driving. UbiGreen makes use of sensors to semi-automatically infer transportation mode and monitor users' transportation behaviours.

Table 3. The persuasive systems for sustainable mobility we identified in the literature.

\begin{tabular}{ccccl}
\hline Ref. & Year & System & Type & Implemented Persuasive Strategies \\
\hline$[3]$ & 2003 & TRIPZOOM & Mobile & $\begin{array}{l}\text { Self-monitoring, Challenges \& Goal Setting, Social } \\
\text { comparison }\end{array}$ \\
{$[6]$} & 2007 & PerCues & Mobile & Self-monitoring \\
{$[7]$} & 2009 & UbiGreen & Mobile & Self-monitoring \\
{$[16]$} & 2009 & Ecoisland & Mobile/web & Social comparison, Gamification, Challenges \& Goal Setting \\
{$[9]$} & 2011 & iTour & Mobile & Tailoring, Suggestion, Social comparison \\
{$[17]$} & 2011 & Green Daily Guide & Mobile & Rewards, Gamification \\
{$[8]$} & 2013 & QT & Mobile/web & Self-monitoring, Social comparison \\
{$[35]$} & 2013 & MatkaHupi & Mobile & Self-monitoring, Challenges \& Goal Setting \\
{$[13]$} & 2013 & SUPERHUB & Mobile & Self-monitoring, Challenges \& Goal Setting, Social \\
{$[10]$} & 2014 & IPET & Mobile & Somparison, Tailoring, Gamification \& Rewards \\
{$[11]$} & 2014 & Peacox & Mobile/web & Self-monitoring, Tailoring \\
{$[12]$} & 2014 & Moves & Mobile & comparison, Tailoring, Gamification \& Rewards \\
{$[40]$} & 2014 & Srom5To4 & Web & Gamification, Comparison, Rewards \\
{$[14]$} & 2015 & Viaggia Roveretgoto & Mobile & Gamification \& Rewards \\
{$[18]$} & 2015 & E-Mission & Mobile & Gamification, Challenges \& Goal Setting, Self-monitoring \\
{$[42]$} & 2016 & StreetLife & Mobile & Gamification \\
{$[24]$} & 2016 & SaveMyBike & Web & Rewards, Self-monitoring \\
{$[25]$} & 2016 & BikeTogether & Mobile & Self-monitoring, comparison, cooperation \\
{$[26]$} & 2017 & EcoTrips & Mobile & Self-monitoring \\
{$[41]$} & 2018 & GreenCommute & Web & Rewards, Social comparison \\
{$[27]$} & 2018 & Motivate & Web & Self-monitoring, Gamification, Simulation, Rewards \\
{$[43]$} & 2018 & SMART & Mobile & Gamification, Rewards \\
{$[28]$} & 2018 & Optimum & Mobile & Self-monitoring, Comparison, Suggestion \\
\hline & \multicolumn{5}{r}{}
\end{tabular}

Ecoisland [16] is a game-like application intended to be used through their normal daily activities by a family who wants to behave in a more ecological way.

I-Tour [9] is a personal mobility assistant that promotes the use of public transport by helping user identify the best travel option across a multi-modal transport network through a user-friendly interface that intelligently adjusts to user preferences and to contextual information.

Green Daily Guide [17] is a mobile application that motivates people to use public transport or other alternative means of transportation instead of private cars. The application is intended to take a part in the journey planning to prompt users to choose the smartest way of traveling.

The Quantified Traveller (QT) [8] app provides a computational alternative to counsellors of travel feedback programs. It collects travel information and feeds it back to in the form of "augmented" travel diaries in order to encourage pro-environmental mobility. The presented information includes personalized carbon, exercise, time, and cost footprint, while the design also embodies social comparisons.

MatkaHupi [35] is a journey planning app that detects and records users' trips and transport modes and provides eco-feedback in the form of visualization of $\mathrm{CO}_{2}$ emissions. Moreover, the app employs a gamification approach for persuasion in the form of challenges offered to users based on their observed behaviour. After a trip, the app checks for faster and/or with lower emissions alternatives which are presented to the user. $\mathrm{S} /$ he is then challenged to consider the proposed alternative in the future and rewarded with points if the challenge is accepted and achieved.

SUPERHUB [13] is a mobile app which motivates users making more sustainable choices using a novel combination of goal-setting, self-monitoring, rewards, and sharing features. It supports 
multi-modal journey planning, personalized recommendations, and behaviour change for environmentally sustainable travel. There are also many functionalities, such as event reporting, social media, and transport data-feed scanning, that aim to more self-contained, comprehensive, and accurate user experience.

The IPET platform [10] integrates functionalities for the provision of persuasive information and advice to mobile devices. More specifically, it tracks user activities, analyses them to detect the used trip mode, and infers alternative and more sustainable routes that are communicated to the user using brief persuasive messages that combine text and images in different, including comics and real-life sceneries.

Peacox [11] influences urban travellers to consider the environmental friendliness of travel modes while planning a route. A choice architecture approach nudges users to shift to less polluting modes by filtering and structuring the alternative routes according to user preferences and contexts while emphasizing the environmentally friendly routes. Moreover, the app embeds $\mathrm{CO}_{2}$ emissions visualizations as well as personal and collaborative challenges aiming to persuade users to reduce the emissions caused by their mobility choices.

Moves [12] is an activity tracking app that provides data on the user's time and distance spent under each active mode, using a combination of accelerometer and location data to distinguish between motorized transportation cycling, walking, and running. Users can view daily or weekly activity summaries as well as a daily record of their locations and trips.

From5To4 [40] is web-based tool which combines personal and group incentives for employees into an attractive game. It aims for a reduction of the energy impact of commuter and business trips. It encourages employees to change their travel behaviour and use sustainable modes for at least $20 \%$ of their travel to work trips.

Viaggia Roveretgoto [14] provides gamification mechanisms to incentivize sustainable mobility choices. It integrates a journey planner that highlights in green the most sustainable options and presents them first. Users are rewarded with points based on the modes they use (including Green points for sustainable transportation, Health points for biking or walking, and Park\&Ride points for repeated park and ride facilities use).

E-mission [18] motivates users to make more sustainable mobility choices by using gamification and data visualization. It is a self-tracking mobile phone app that detects mobility patterns, predicts trips, and provides the carbon footprint of users in order to change their behavior.

Streetlife [42] provides a gamification approach to engage users reliably to change respective mobility routines and to replace them with new routines.

SaveMyBike [24] is a service that aims to increase the use of sustainable means of transport in urban areas and to improve air quality through good mobility practice rewarding by monitoring individual trips.

BikeTogether [25], a mobile app for cycle commuting, allows users to figuratively cycle together while being connected over the Internet. A bicycle flashlight is used as a metaphor for users to feel accompanied and guided.

EcoTrips [26] is a mobile application that promotes walking and biking for short trips by tracking users' travel behavior and providing feedback related to fitness, finances, and time management.

GreenCommute [41] is a recommendation system that facilitates commuters to make environmental friendly choices. The system quantifies the utility of recommendations from a user and social perspective and provides rewards to users by balancing the conflicts between the perspectives.

MOTIVATE [27] offers a simplified experiential procedure for understanding the consequences of mode choice and sustainable decision making. Also, an agent of mobility planning provides travel data and opinions for the improvement of city's daily transportation performance, while a reward system motivates user to change their behavior.

SMART [43] is a mobile application that helps users to travel smarter and be more environmentally aware, for example, by avoiding traffic jams or by choosing a different mode of transport. SMART 
focuses on optimizing travel behaviour in a human-centred approach, targeted at commuters, city visitors, event visitors, and shoppers.

OPTIMUM [28] is a route planning application that leverages persuadability profiles comprising of users' personality and mobility type in order to identify the persuasive strategy that fits best to the user's profile and provides targeted interventions in the form of persuasive messages that persuade users to select more environmentally friendly routes.

In terms of employed technology, most systems are implemented as mobile applications, with a total of 16 mobile implementations. Three are implemented as combined mobile and web applications, and four are web applications. Figure 5 depicts the implementation types of the identified systems.

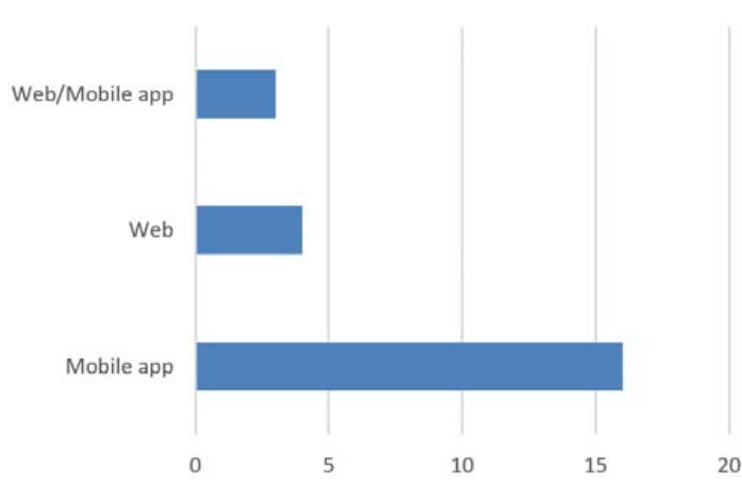

Figure 5. Implementation types of the identified systems.

\subsection{Evaluation of Persuasive Technologies for Sustainable Mobility}

Table 4 presents the main details of the pilot studies examined, including the goal, the number of users involved, the place where the study took place, and the way that the goal achievement was evaluated. Not surprisingly, all studies have a similar goal, i.e., to promote sustainable mobility and to change travel behaviour using different persuasion strategies.

Table 4. Main implementation details of the studies we examined including their focus, number of users, country, and type of evaluation.

\begin{tabular}{|c|c|c|c|c|c|}
\hline Ref./Year & Focus of the Proposed Approach. & Users & Place & Duration & Evaluation Type \\
\hline$[6] / 2007$ & $\begin{array}{l}\text { Persuade people to shift from using their cars } \\
\text { to public transportation. }\end{array}$ & 54 & Austria & not available & Qualitative \\
\hline [7]/2009 & $\begin{array}{l}\text { To understand how participants react on } \\
\text { visual feedback of } \mathrm{CO}_{2} \text { emissions. }\end{array}$ & 14 & USA & 3 weeks & Qualitative \\
\hline$[8] / 2013$ & $\begin{array}{l}\text { To explore whether travel feedback program } \\
\text { can be replicated by a computational system. }\end{array}$ & 135 & USA & 3 weeks & Mixed \\
\hline [9]/2013 & $\begin{array}{l}\text { To explore users' reaction to actionable } \\
\text { mobility challenges presented through a } \\
\text { journey planning app. }\end{array}$ & 12 & Finland & 4 weeks & Mixed \\
\hline$[11] / 2014$ & $\begin{array}{l}\text { To explore the effects of persuasive strategies } \\
\text { and choice architecture in journey planning } \\
\text { systems for sustainable transportation. }\end{array}$ & 24 & Austria & 8 weeks & Mixed \\
\hline$[10] / 2014$ & $\begin{array}{l}\text { To understand the impact of persuasive } \\
\text { information and advices delivered through } \\
\text { mobile devices on car usage reduction. }\end{array}$ & 15 & Italy & 2 weeks & Mixed \\
\hline$[13] / 2013$ & $\begin{array}{l}\text { To explore the impact of a journey planner } \\
\text { app integrating goal-setting, self-monitoring, } \\
\text { rewards and sharing features on transport } \\
\text { choices and habits. }\end{array}$ & 8 & Italy & 4 weeks & Mixed \\
\hline [12]/2014 & $\begin{array}{l}\text { To promote active modes such as bicycling } \\
\text { and walking with the use of activity tracking } \\
\text { smartphone applications. }\end{array}$ & 35 & USA & 3 weeks & Mixed \\
\hline
\end{tabular}


Table 4. Cont.

\begin{tabular}{|c|c|c|c|c|c|}
\hline Ref./Year & Focus of the Proposed Approach. & Users & Place & Duration & Evaluation Type \\
\hline$[14] / 2015$ & $\begin{array}{l}\text { To explore the potential of gamification } \\
\text { mechanisms to incentivize behavioural } \\
\text { changes toward sustainable } \\
\text { mobility solutions. }\end{array}$ & 40 & Italy & 5 weeks & Quantitative \\
\hline$[34] / 2016$ & $\begin{array}{l}\text { Persuade elderly users to adopt sustainable } \\
\text { mobile behaviour. }\end{array}$ & 7 & Germany & 4 weeks & Qualitative \\
\hline$[16] / 2009$ & Persuading users to reduce $\mathrm{CO}_{2}$ emissions & 20 & Japan & 4 weeks & Quantitative \\
\hline$[33] / 2013$ & To reduce car usage. & 720 & Germany & not available & Mixed \\
\hline$[18] / 2015$ & $\begin{array}{l}\text { To incentivize people to reduce their } \\
\text { carbon footprint. }\end{array}$ & 67 & USA & 4 weeks & Mixed \\
\hline$[45] / 2011$ & $\begin{array}{l}\text { To persuade drivers to adopt safer } \\
\text { driving behaviours. }\end{array}$ & 194 & $\begin{array}{l}\text { CATCH project } \\
\text { participant }^{1}\end{array}$ & not available & Quantitative \\
\hline$[31] / 2013$ & To reduce car usage. & 720 & Germany & not available & Mixed \\
\hline$[19] / 2016$ & $\begin{array}{l}\text { To encourage sustainable mobility behaviour } \\
\text { by promoting bike usage. }\end{array}$ & 973 & $\begin{array}{c}\text { online survey } \\
\text { via email }\end{array}$ & 3 weeks & Qualitative \\
\hline$[20] / 2016$ & $\begin{array}{l}\text { To examine the strategies employed in } \\
\text { gamified biking campaigns with the aim of } \\
\text { changing accustomed mobility } \\
\text { behaviour patterns. }\end{array}$ & 25 & USA & 4 weeks & Mixed \\
\hline$[21] / 2016$ & $\begin{array}{l}\text { Persuade users to adopt a more sustainable } \\
\text { mobility behaviour. }\end{array}$ & 3400 & Belgium & 6 months & Mixed \\
\hline$[22] / 2017$ & $\begin{array}{l}\text { Promote a more environmentally conscious } \\
\text { urban mobility paradigm }\end{array}$ & 36 & Italy & 9 weeks & Mixed \\
\hline [23]/2015 & $\begin{array}{l}\text { To sustain the use of environmentally } \\
\text { friendly transport modes through individual } \\
\text { and collaborative challenges. }\end{array}$ & 37 & Ireland & 2 months & Mixed \\
\hline$[42] / 2016$ & $\begin{array}{l}\text { To convince users to leave their "mobility } \\
\text { comfort zone". }\end{array}$ & 118 & Germany & 3 months & Qualitative \\
\hline$[24] / 2016$ & $\begin{array}{l}\text { To increase the use of sustainable means of } \\
\text { transport in urban areas. }\end{array}$ & $\begin{array}{l}\text { Italian } \\
\text { citizens }\end{array}$ & Italy & 4 years & Qualitative \\
\hline$[40] / 2014$ & $\begin{array}{l}\text { Reduction of the energy impact of commuter } \\
\text { and business trips through a competition }\end{array}$ & 60 & Netherlands & 6 months & Mixed \\
\hline [29]/2017 & $\begin{array}{l}\text { Examination of the role of emissions } \\
\text { information in transport behaviour }\end{array}$ & 21 & Ireland & 7 weeks & Qualitative \\
\hline$[30] / 2013$ & To increase walking & 518 & Netherlands & 7 weeks & Mixed \\
\hline$[36] / 2014$ & $\begin{array}{l}\text { To facilitate more sustainable } \\
\text { travel behaviour }\end{array}$ & 195 & Sweden & 6 months & Qualitative \\
\hline$[25] / 2016$ & To increase biking & 10 & China & 1 week & Mixed \\
\hline$[41] / 2018$ & $\begin{array}{l}\text { To persuade users make more sustainable } \\
\text { mobility choices }\end{array}$ & 11 & USA & 1 week & Mixed \\
\hline$[28] / 2018$ & $\begin{array}{l}\text { To persuade users make more environmental } \\
\text { friendly mobility choices }\end{array}$ & 27 & Austria & 6 weeks & Mixed \\
\hline
\end{tabular}

${ }^{1}$ https://cordis.europa.eu/project/rcn/92597_en.html.

With respect to the number of users, we observe that in most studies it is fairly small. In all cases, the number of participants is under 200, with the exception of studies $[19,21,30]$. The geographical spread of the analysed studies spans across 12 different countries. Five of the studies took place in Italy, six in the USA, three in Austria, the Netherlands, Ireland, and Germany, while one study has been conducted in each of the following countries: Spain, Finland, Belgium, Sweden, Japan, and China. Note that two studies $([19,45])$ do not report the place where the related work took place. As far as the evaluation type is concerned, most of the studies report results both objective through log analysis and subjective through questionnaires and/or interviews, with the exception of $[14,16,45]$, which report objective evaluations and studies $[6,7,16,19,21,24,25,29]$ report subjective evaluations with qualitative surveys only. 


\subsubsection{Evaluation Methodologies}

Figure 6 summarizes the evaluation methodology employed by the reviewed papers. Quantitative methodologies are based on the analysis of tracking data and questionnaires, whereas qualitative methodologies rely on user interviews and focus group discussions. The mixed method is the dominant method, which means that most studies combine both quantitative and qualitative evaluation approaches. Of all the studies, $46 \%$ employed only qualitative methodologies. The most frequently used qualitative methods are user interviews, focus-group discussions and observation of participants' behaviours and transportation means use. Last, the use of only quantitative methodologies is used in $4 \%$ of the studies. The most commonly used approach for collecting quantitative data is questionnaires and surveys.

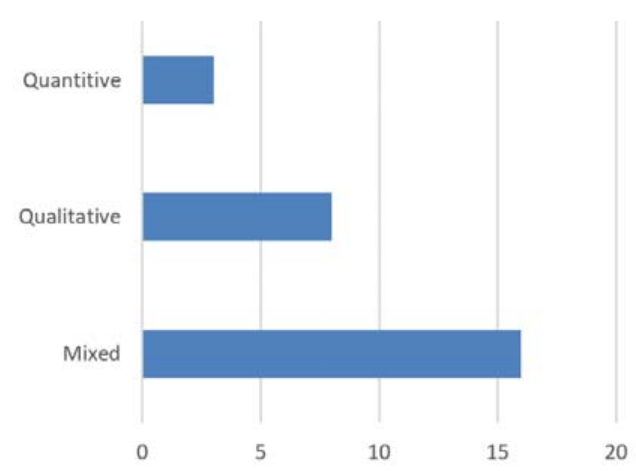

Figure 6. Employed evaluation methodologies and number of studies.

\subsubsection{Type of Outcome Evaluated}

The type of outcome evaluated refers to the effect of the persuasive technologies measured by the selected studies of this review. The most obvious outcome measured is the behavioural effect, i.e., the impact of the persuasive technologies on behavioural change. Commonly, this is measured by monitoring users' behaviour before and after the use of the persuasive technologies in order to understand whether users change their actions and behaviour or not. Data which are used to infer changes in users' behaviour include self-reported activity logs, gps logs, cell phone tracking over the mobile network, as well as qualitative data from interviews with users who provide subjective opinions and statements related to behaviour changes. Focusing on measuring behavioural changes is probably the most accurate method to evaluate the impact of the persuasive interventions. However, it is not always possible to measure or accurately determine actual behavioural change. The main reason is the limited usage period of the persuasive technologies. A usage period of a few weeks is not sufficient to understand the effect of an intervention, and in the transportation domain where travel habits can be difficult to change, the case becomes even harder.

Nonetheless, it is possible to evaluate and measure the impact of the persuasive technologies through the use of different metrics. In the analysed studies we identified four main alternatives: attitude, motivation, awareness and intention. Attitude change is reported two studies $([6,10])$ and the related metrics focus on measuring changes in the attractiveness of environmentally friendly transportation modes as well as in attitudes toward the environment. In [6], the authors directly ask participants to state whether the persuasive technologies have the potential to change their attitude toward public transport, while in [10], the authors use standardised questionnaires. More specifically attitude changes toward transport modes is measured with the scale proposed by [48], while environmental attitude changes are measured by the perceived ability to actually do something positive for the environment [49] and the subscales of Environmental Concern [50] and subscale Sustainable Mobility [51].

Last, certain papers focus on evaluating the implemented systems or approaches. The aim here is to gather results related to the usability and user acceptance of a system or verify the 
acceptance of a proposed approach. In [16], the authors evaluate certain functionalities of a novel route planning application that integrates persuasive features, including, battery consumption, clearness of presented information, and perceived impact on potential behavioural change. Table 5 summarizes the abovementioned types of outcomes evaluated and the corresponding studies.

Table 5. Type of outcome evaluated in the studies we examined.

\begin{tabular}{lcc}
\hline Evaluation Target & \% of Total Studies ${ }^{1}$ & Study \\
\hline Behavioural Change & $62.9 \%$ & {$[6,8,10,12-14,16,20-25,28,29,31,33,41]$} \\
\hline Attitude Change & $11 \%$ & {$[6,9,10]$} \\
\hline $\begin{array}{c}\text { System/approach evaluation only } \\
\text { (usability, acceptance, functionalities, }\end{array}$ & $48.6 \%$ & {$[7-9,11,18,19,28-31,36,40,42,45]$} \\
perceived impact on behavioural change) & & \\
$\begin{array}{l}\text { 1 Note that the sum of the percentages provided in the table does not add up to } 100 \text { as there are studies that report } \\
\text { more than one evaluation targets (i.e., studies that report results on users' behavioral change as well as results on } \\
\text { the evaluation of the system/approach used in the study). }\end{array}$
\end{tabular}

\subsection{Results of Persuasive Technologies Evaluations and Impact on Travel Behaviour}

This section summarizes the evaluation results of the studies reviewed in this paper. We focus only on the studies which measured, or reported results related to behavioural changes. We identified studies that reported successful results, i.e., they conclude that one of the evaluation targets was achieved (actual behavioural change was observed, attitude change was achieved, or the system/approach was well perceived by participants), studies that are partially successful, i.e., they conclude that some effects were observed, but further experiments are needed to verify the results, and studies that were not successful, i.e., the results were not successful for the evaluation target. The results are summarized in Table 6 . Overall, $65 \%$ of the studies report successful results, $18 \%$ not successful, and $33 \%$ partially successful.

Table 6. Results of the evaluation outcomes per evaluation target of persuasive technology studies.

\begin{tabular}{|c|c|c|}
\hline Outcome & $\%$ of Total Studies ${ }^{1}$ & Evaluation Targets and Studies \\
\hline Successful & $65 \%$ & $\begin{array}{l}\text { Behavioural Change: }[8,12-15,20-23,31,33,40] \\
\text { Attitude Change: }[10] \\
\text { System/Approach: }[6-11,13,16,18-21,23-25,28-30,33,34,36,40,42,45]\end{array}$ \\
\hline $\begin{array}{c}\text { Partially } \\
\text { successful }\end{array}$ & $33 \%$ & $\begin{array}{l}\text { Behavioural Change: }[6,7,11,19,20,29,31,41] \\
\text { Attitude Change: }[6] \\
\text { System/Approach: }[9,31]\end{array}$ \\
\hline $\begin{array}{c}\text { Not } \\
\text { successful }\end{array}$ & $18 \%$ & $\begin{array}{l}\text { Behavioural Change: }[10,16,30,36] \\
\text { Attitude Change: }[9] \\
\text { System/Approach: - }\end{array}$ \\
\hline
\end{tabular}

${ }^{1}$ Note that there are studies that report more than one evaluation targets.

Table 7 provides an overview of the evaluation results for individual persuasive strategies in the studies that employ them. We notice that a higher number of studies has focused on implementing and evaluating the strategies of Self-monitoring \& Feedback, Gamification \& Rewards, and Challenges \& Goal Setting. In the cases of Suggestion, Reduction, Tunnelling, and Simulation, there are no positive behavioural changes reported, but this can be due to the fact that these strategies are evaluated in a limited number of studies only. System and approach evaluations are commonly positive, which means that normally users are content with their use. However, the limited results on the impact of the examined persuasive strategies on actual behavioural change indicates the need for more studies of longer durations that focus more on evaluating their impact on users' behaviour rather than on evaluating the system and approach implementations. 
Table 7. Persuasive strategies and the reported evaluation results per evaluation target of persuasive technology studies. BC stands for Behavioural Change, A stands for Attitude Change, and S/A stands for System/Approach.

\begin{tabular}{|c|c|c|c|c|}
\hline $\begin{array}{l}\text { Persuasive } \\
\text { Strategy }\end{array}$ & $\begin{array}{l}\text { Evaluation } \\
\text { Target }\end{array}$ & $\begin{array}{c}\text { Studies with } \\
\text { Successful Outcome }\end{array}$ & $\begin{array}{l}\text { Studies with Partially } \\
\text { Successful Outcome }\end{array}$ & $\begin{array}{l}\text { Studies with } \\
\text { Non-Successful } \\
\text { Outcome }\end{array}$ \\
\hline \multirow{3}{*}{$\begin{array}{l}\text { Challenges \& } \\
\text { Goal Setting }\end{array}$} & BC: & {$[13,20,22]$} & {$[19,23]$} & [16] \\
\hline & A: & - & - & - \\
\hline & S/A: & {$[13,19-23]$} & - & - \\
\hline \multirow{3}{*}{$\begin{array}{l}\text { Self-monitoring } \\
\text { and Feedback }\end{array}$} & BC: & {$[8,12,13,22,31,33]$} & {$[6,7,11,19,41]$} & {$[29,30]$} \\
\hline & A: & - & [6] & [9] \\
\hline & S/A: & {$[6-8,11,13,18,19,22,24,25,29,30,34]$} & [9] & - \\
\hline \multirow{3}{*}{ Tailoring } & BC: & [13] & {$[11,23,36]$} & [10] \\
\hline & A: & [10] & - & - \\
\hline & S/A: & {$[10,13,21,23]$} & [36] & - \\
\hline \multirow{3}{*}{$\begin{array}{c}\text { Social } \\
\text { comparison }\end{array}$} & BC: & {$[8,13,40,45]$} & - & [36] \\
\hline & A: & - & - & - \\
\hline & S/A: & {$[8,13,16,20,21,28,30,40]$} & - & - \\
\hline \multirow{3}{*}{$\begin{array}{l}\text { Gamification \& } \\
\text { Rewards }\end{array}$} & BC: & {$[13,14,22,40,42]$} & {$[7,19,36]$} & {$[16,30]$} \\
\hline & A: & - & - & - \\
\hline & S/A: & {$[7,13,16,19,22,24,34,40,42]$} & [36] & - \\
\hline \multirow{3}{*}{ Suggestion } & BC: & - & [23] & [10] \\
\hline & A: & [10] & - & - \\
\hline & S/A: & {$[10,23]$} & - & - \\
\hline \multirow{3}{*}{ Reduction } & BC: & - & [23] & [10] \\
\hline & A: & [10] & - & - \\
\hline & S/A: & {$[10,23]$} & - & - \\
\hline \multirow{3}{*}{ Tunnelling } & BC: & - & [23] & [10] \\
\hline & A: & [10] & - & - \\
\hline & S/A: & {$[10,23]$} & - & - \\
\hline \multirow{3}{*}{ Simulation } & BC: & - & [23] & [10] \\
\hline & A: & [10] & - & - \\
\hline & S/A: & {$[10,23]$} & - & - \\
\hline \multirow{3}{*}{ Framing } & BC: & - & - & - \\
\hline & A: & - & - & - \\
\hline & S/A: & [45] & - & - \\
\hline
\end{tabular}

\section{Discussion and Research Challenges}

In the following sections, we analyse and discuss the main findings from our review. Moreover, we provide a set of research directions that can shape future research on persuasive technologies for sustainable transportation. Table 8 summarizes our findings and provides references to the sections that follow and provide more detailed discussion.

Table 8. Summary of findings, including barriers and opportunities for future research.

\begin{tabular}{ll}
\hline Finding & Barriers/Future Opportunities \\
\hline $\begin{array}{l}\text { The majority of PT pilots are deployed in countries } \\
\text { with advanced multimodal transport systems, in } \\
\text { Europe and the US (Section 4.1). }\end{array}$ & $\begin{array}{l}\text { PT require the availability and accessibility of green } \\
\text { transportation alternatives. } \\
\text { There is a great opportunity to deploy PT in areas where } \\
\text { environmental pollution is a critical issue. }\end{array}$ \\
\hline $\begin{array}{l}\text { Most PT pilots run for short periods of time (up to } \\
\text { two months) and do not capture long term and/or } \\
\text { seasonality effects (Section 4.2). }\end{array}$ & $\begin{array}{l}\text { Contextual parameters (e.g., weather, travellers' daily routines) } \\
\text { may vary throughout the year and affect the success of PT. } \\
\text { Long term studies are needed in order to identify the long term } \\
\text { impact of PT as well as their impact at different times of the year. }\end{array}$ \\
\hline
\end{tabular}


Table 8. Cont.

\begin{tabular}{|c|c|}
\hline Finding & Barriers/Future Opportunities \\
\hline $\begin{array}{l}\text { The analysed studies do not provide an analysis of } \\
\text { the area/transport system where the PT are deployed } \\
\text { (Section 4.2). }\end{array}$ & $\begin{array}{l}\text { PT cannot nudge travellers to sustainable transport modes if } \\
\text { such modes are not available. } \\
\text { Integrated approaches where the transport system works for the } \\
\text { benefit of travellers and persuasive technologies support } \\
\text { travellers' decisions could provide significant impact. }\end{array}$ \\
\hline $\begin{array}{l}\text { User profiles and current habits can affect the use and } \\
\text { impact of PT and system designers should not expect } \\
\text { that all users can change their behaviour and } \\
\text { completely switch to a greener mode of transport } \\
\text { (Section 4.2). }\end{array}$ & $\begin{array}{l}\text { Most of the persuasive systems and related evaluations do not } \\
\text { provide an analysis of the impact on specific traveller profiles } \\
\text { (i.e., the impact on frequent drivers, public transport users, etc.) } \\
\text { Future studies should provide evidence of the impact on specific } \\
\text { traveller profiles. }\end{array}$ \\
\hline $\begin{array}{l}\text { We identified eleven persuasive strategies which } \\
\text { have been implemented in the form of additional } \\
\text { features in mobile route planners or as standalone } \\
\text { applications (Section 4.3). }\end{array}$ & $\begin{array}{l}\text { The current state of the art does not include a holistic application } \\
\text { which can be used to support all the stages of behavioural } \\
\text { change theoretical models, starting from a pre-decisional stage } \\
\text { and guiding the user all the way up to the post-actional stage } \\
\text { and maintenance of sustainable behaviours. }\end{array}$ \\
\hline $\begin{array}{l}\text { Personalization is seen as an important possibility to } \\
\text { improve the impact of the systems and to increase } \\
\text { acceptability and real-life usage (Section 4.4.1). }\end{array}$ & $\begin{array}{l}\text { Creation of services that address the needs of individual users } \\
\text { and tailor persuasive strategies to individual users. }\end{array}$ \\
\hline $\begin{array}{l}\text { Contextualization of interventions, which refers to } \\
\text { providing the right information at the right time and } \\
\text { location, is considered important in order to deliver } \\
\text { more relevant interventions (Section 4.4.2). }\end{array}$ & $\begin{array}{l}\text { Consideration of users' personality for contextualizing } \\
\text { persuasive interventions. }\end{array}$ \\
\hline $\begin{array}{l}\text { Good timing of interventions is important both for } \\
\text { increasing the impact of the system and acceptance } \\
\text { by users (Section 4.4.3). }\end{array}$ & $\begin{array}{l}\text { Identify methods to deliver persuasive interventions at the } \\
\text { appropriate time without annoying users. }\end{array}$ \\
\hline
\end{tabular}

\subsection{General Observations}

The first papers that deal with persuasive technology in transport applications emerge in 2003, while in recent years, we observe a tendency of increased number of papers and corresponding researchers who apply persuasive technologies in this domain. This is in line with the increased interest of researchers in the field of persuasive technologies, driven by the widespread adoption of ubiquitous technologies, including smartphones, which provide the means to apply such technologies, as well the pressing need for moving toward sustainable behaviours. As we are at the first stages of understanding the impact and power of persuasive technology, we expect that the increasing tendency of published work to continue in the coming years.

With respect to the country of origin of the related work, most of the studies originate from the US, Italy, Austria, Germany, and Ireland. We attribute the interest for persuasive technology in such countries to the fact that they constitute ideal testbeds for implementing related solutions as they have deployed advanced transportation systems and focus on solving problems of transport sustainability. Furthermore, in such counties, there are multimodal options and availability of open data which can be used to implement solutions which support travellers to establish green transportation habits. Moreover, travellers are familiar with the use of technology for supporting them in daily trips. Last but not least, we see that such countries have strategic policy objectives for transitioning to more sustainable mobility. It is interesting that we identified only one related paper from countries like China where sustainable transportation is an issue and we would expect greater interest in this field.

\subsection{Effectiveness of Persuasive Technology for Sustainable Mobility}

As presented above, we identified 44 studies of persuasive technology for sustainable mobility. It is difficult to provide a clear conclusion on whether the effect of such technologies leads to long-term behavioural change and change of habits toward sustainable transportation modes. In the majority of the studies the persuasive technology interventions have been applied for a period of one to two months (19 out of 27 studies). In five studies, the interventions were applied for a period of three to 
six months, while one study spanned in a timeframe of four years. The fairly short timeframes fail to capture important aspects such as seasonality and the effectiveness on a longer-term basis. Seasonality is an important factor for habits related to transportation as there are several important contextual parameters which vary throughout the year and affect user decisions, with the most important being the weather and the everyday schedule of travellers. When the weather is warm and sunny, it should be easier for travellers to switch to greener transport modes. However, in the winter time, it can be difficult to move away from using a personal car. Moreover, during the winter time, most people have a daily routine that can be a barrier when asking them to switch modes. A parent that has to get his children to the school in a hasty morning may not switch modes; however, when schools are closed, the same person can make the decision to switch to public transport or other green modes.

Another important aspect that is not considered in the evaluation studies refers to the barriers in the transport options of the area where the intervention is deployed. The assumption for a successful behavioural change system is the availability and accessibility of green transportation alternatives. Practically, this means that the chances of convincing a traveller who lives in an area without public transport to switch to public transport are potentially non-existent. Besides modes' availability, other important factors that can constitute barriers include the reliability of the transport system (e.g., frequent service interruptions can deter travellers from using public transportation), the ease of accessing the modes (e.g., e-tickets, accessible bus stops, location of bike sharing infrastructure, etc.). The identified studies do not analyse such barriers and rely on the assumption that the persuasive technology alone can result to behavioural change. Our understanding is that the deployment of persuasive interventions should be part of a general transport planning approach, in cooperation with the transport authorities and various transport modes operators. An integrated approach where the transport system works for the benefit of travellers and persuasive technologies support travellers' decisions could provide a significant impact.

Furthermore, our analysis has shown that most of the persuasive systems and related evaluations do not provide an analysis of the impact on specific traveller profiles (i.e., the impact on frequent drivers, public transport users, etc.). Instead, they provide aggregate results for a wide range of traveller profiles without considering specific user groups and the impact that can be delivered to each group. The most impactful interventions would be those delivered to car users, since changing the behaviour of a frequent driver to use public transport or other greener modes of transport should provide greater benefits than changing the behaviour of a public transport user to take e.g., a bicycle or walk. Typologies of $\mathrm{CO}_{2}$ emissions caused by modes of transport combinations, such as the one depicted in section 1 of Figure 7, are fundamental in allowing to select the target of persuasive interventions, in terms of transportation modes or their combinations, for user groups of particular mobility behaviour/type. Based on such a typology, persuasive system designers should nudge users toward selecting modes with less $\mathrm{CO}_{2}$ emissions than the mode they commonly use or sustain their behaviour in case they already use green modes. The selection of target modes depends on the current mobility type of the user and the basic typology of $\mathrm{CO}_{2}$ emissions. Indicative examples depicted in section 2 of Figure 7 include (i) a user A who commonly takes her/his car should be nudged to opt for modes such as car sharing or park and ride and (ii) a user B who commonly takes public transportation should be nudged to sustain her/his behaviour and consider modes like bike, bike sharing, and walk when possible.

In any case, system designers should not expect that all users can change their behaviour and completely switch to a greener mode of transport. Instead the most realistic line of thinking is that there are opportunities in specific occasions of the daily travels of users that can be leveraged in order to persuade them to follow more environmentally friendly modes. There are two main positive consequences when such occasions are identified, and users follow greener modes: (i) on an aggregate level, there can be significant $\mathrm{CO}_{2}$ savings and improvements in the transportation system and (ii) on an individual level, certain users can discover green transportation alternatives that fit their preferences and change their long-term behaviour. 

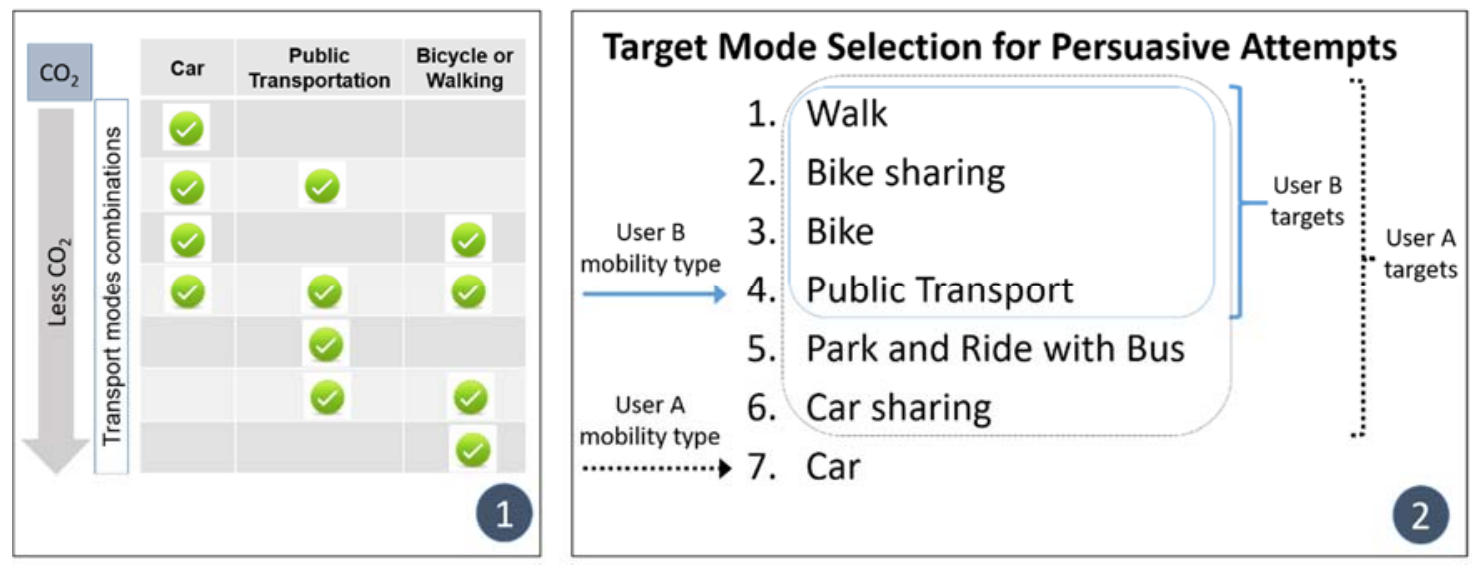

Figure 7. A basic typology for $\mathrm{CO}_{2}$ emissions caused by modes of transport combinations is presented in section 1 of the figure, where the different combinations are ranked based on the emissions produced according to [44]. As shown in section 2 of the figure, a persuasive app should consider users' mobility type and nudge her/him toward selecting modes and modes combinations that result to less emissions.

\subsection{The Relationship between Persuasive Technology and Behavioural Change Theories}

Since the inception of the term persuasive technology, the majority of research has focused on the implementation of already available persuasive strategies that have been commonly designed and studied in the realms or marketing, social psychology and behavioural economics [36]. In our review, we identified 11 persuasive strategies which have been implemented in the form of additional features in mobile route planners or as standalone applications. Most approaches focus on providing challenges and goals (six systems), self-monitoring and feedback information (15 systems), social comparison (11 systems), gamification and rewards (10 systems), and personalized messages (four systems). These systems rely on capturing data from users' mobility patterns and using these data for implementing the relevant strategies.

Theoretical models of behavioural change provide more holistic frameworks and describe a stage process of actions which eventually results to change of behaviour and habits as well as the maintenance of the new behaviour. Most of these models have been developed in the domain of health and focus on changing users' habits toward healthier behaviours. Indicative examples include the Trans-Theoretical model of health behaviour change [52], the Theory of planned behaviour [53], and the model of action phases [54]. The recent work of [31] tries to adjust such models for environmental sustainability and specifically for the domain of transportation. The main idea refers to establishing a model for changing environmentally harmful behaviour due to mobility decisions. The model defines four stages of behavioural change:

Pre-decisional: This stage refers to individuals who are satisfied with their current behaviour and do not feel the need to change. A persuasive system targeting such users should provide constructs which will nudge users toward the formation of a goal intention. For example, the system could create awareness on the negative impact of unsustainable behaviour and provide suggestions of behavioural actions which can lead to sustainable behaviour.

Pre-actional: This stage refers to individuals who are willing to change their behaviour but do not know how to achieve this goal. A persuasive system can provide suggestions on sustainable mode usage for everyday trips and statistics on the negative consequences of the current behaviour compared to a more sustainable one.

Actional: This stage refers to individuals who have formed a behavioural intention and have chosen a specific goal to reach their goal. A persuasive system can track travellers' behaviour and present actual statistics on the behaviour change progress, support users in their everyday route 
planning decisions, and provide motivating elements such as gamification and incentives that support users to reach their goal.

Post-Actional: This stage refers to individuals who have implemented behavioural change actions and face the problem of maintaining/intensifying the behaviour. A persuasive system can provide the means to sustain users' interest in sustainable behaviour with functionalities such as motivational elements in the form of messages, incentives and gamification, monitoring of user behaviour, and providing notifications in the case of relapse.

In Figure 8, we have classified the persuasive systems to the four stages described above. There are two applications which manage to address several stages of the model, Peacox [11] and Superhub [13], while the others commonly focus on a single stage. Moreover, the "actional" stage is addressed by a high number of applications. The pre-decisional stage is not addressed by any application, although this is an important stage that triggers subsequent actions. We can conclude that the current state-of-the-art does not include a holistic application that can be used to support all the stages of behavioural change models, starting from a pre-decisional stage and guiding the user all the way up to the post-actional stage and maintenance of sustainable behaviours.

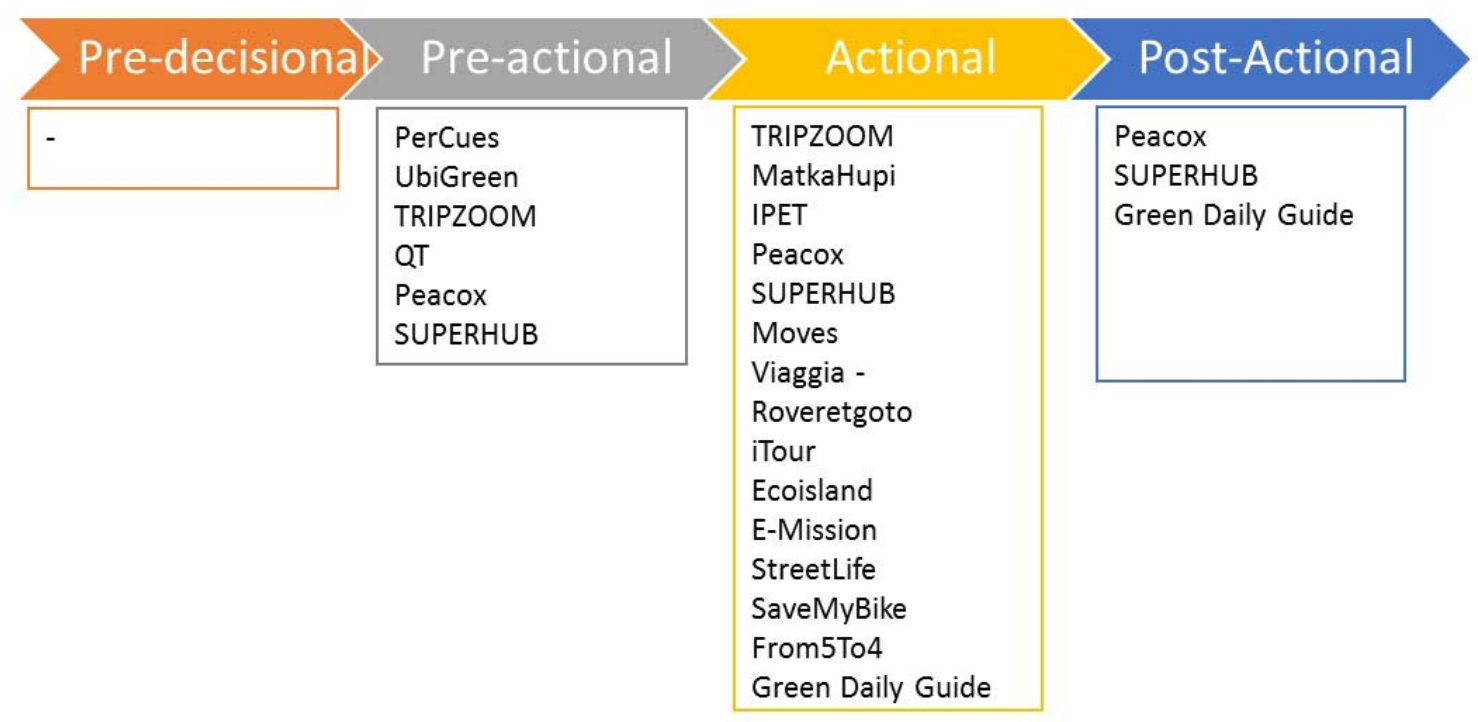

Figure 8. Mapping of the identified persuasive applications to the stage process model of behavioral change of [34].

\subsection{Limitations of Existing Technologies and Future Opportunities}

Our analysis of the systems integrating and implementing persuasive technologies for sustainable urban mobility revealed a set of limitations and trends which are discussed in the related papers. These can serve as recommendations for future system designs. More specifically, summarizing the corresponding information, the following limitations and key observations can be identified:

- Personalization is seen as an important possibility to improve the impact of the systems and to increase acceptability and real-life usage. In the context of mobile persuasion, aspects to consider for personalization purposes are especially route suggestions and alternatives.

- Contextualization of interventions, which refers to providing the right information at the right time and location, is considered important in order to deliver more relevant interventions.

- Good timing of interventions is important both for increasing the impact of the system and the acceptance by the users.

Based on the above observation, we analyse three key technology areas which should be explored by researchers and practitioners in the future. 


\subsubsection{Personalization}

The results of the examined studies show that people differ in their susceptibility to different persuasive strategies. This leads to the assumption that personalized approaches can be more successful than "one size fits all" approaches. Many persuasive applications for sustainability have been implemented for a general audience using a single persuasive technique. For instance, IPET [10] motivates users to more eco-friendly habits providing visual feedback and sending personalized notifications. Thus, it is necessary to create services that address the needs of individual users (e.g., tailoring notifications). Personalization can also sustain users' interest over time by considering the different personality types. Some first results are encouraging, e.g., Jylhä et al., [9] reached better results by personalizing persuasive challenges. However, further exploration of personalized persuasive strategies for behavioural change toward sustainable modes of transportation is required.

\subsubsection{Context Awareness}

Another interesting observation concerns context awareness. Many persuasive applications can be considered context-aware, since they take contextual information into account while persuading users. However, they consider only one or two types of context such as location while ignoring other contextual data such as user context. Similarly, user's personalities (which can be considered a special type of context) are ignored. Persuasive applications employ several persuasion techniques to motivate people to promote more sustainable mobility. However, a large amount of research performed in the area of persuasive technologies widely acknowledges that some of these persuasion methods have a reverse effect on some users. For example, competition as a kind of persuasion technique cannot motivate a broad range of people, and it loses its appeal after a short period of time. By taking into account the personality of users, persuasive applications can tailor persuasion methods and therefore achieve more success.

\subsubsection{Proactivity}

As indicated in [6], timely and proactive delivery of information can enhance the persuasive potential of an approach. Much of conventional choice theory assumes that each individual has complete knowledge of the alternatives and can make a rational choice. More recent empirical research [47] suggests that a much more proactive approach is required to not only inform individuals about the alternatives that are available but also help them decide which is most suitable for them. Information has to be provided to the user at the appropriate time rather than assuming that they will find it themselves.

\section{Conclusions}

In this paper, we reviewed persuasive systems and pilot studies related to behavioral change interventions for sustainable urban mobility. We analysed and discussed the effectiveness and trends of persuasive technology (PT) for transport applications. The review results show that PT is a promising approach for promoting desirable behavior for supporting users to move toward green transportation modes, thus solving a pressuring problem of our urbanised world. A main conclusion is the lack of largescale and longitudinal evaluations, which makes it difficult to establish a solid opinion on the long-term impact of PT at promoting desirable behaviour in the area of urban mobility. However, as the research in this field is beginning to intensify we expect that future results will shed light and provide necessary improvements for rendering the interventions more effective. Toward this direction, we identified the need for holistic approaches that cover various stages of behavioural stages, starting from a pre-decisional stage and supporting the users all the way up to a post-actional stage. Moreover, future research should provide evidence of the value of PT for policy makers and transport operators and identify how PT-based applications can be employed by such stakeholders. This analysis has not been included this paper as our focus has been mainly on the technological aspects. Last but not least, 
we identified a set of technology related research areas, namely personalization, contextualization, and proactivity, that can improve the effectiveness of persuasive interventions and the end-user experience.

Author Contributions: Conceptualization, Methodology, Formal Analysis, Writing-Original Draft Preparation, E.A., E.B. and B.M.; Writing-Review \& Editing, all authors.

Funding: Research reported in this paper has been partially funded by the European Commission project OPTIMUM (H2020 grant agreement No. 636160-2) and the European Commission project MaaS4EU (H2020 grant agreement No. 723176).

Acknowledgments: We thank the three anonymous reviewers for insightful comments and helpful suggestions in improving the manuscript.

Conflicts of Interest: The authors declare no conflicts of interest.

\section{References}

1. Kahn Ribeiro, S.; Kobayashi, S.; Beuthe, M.; Gasca, J.; Greene, D.; Lee, D.S.; Muromachi, Y.; Newton, P.J.; Plotkin, S.; Sperling, D.; et al. Transport and its infrastructure. In Climate Change 2007: Mitigation. Contribution of Working Group III to the Fourth Assessment Report of the Intergovernmental Panel on Climate Change; Metz, B., Davidson, O.R., Bosch, P.R., Dave, R., Meyer, L.A., Eds.; Cambridge University Press: Cambridge, UK; New York, NY, USA, 2007.

2. Pucher, J.; Dijkstra, L. Promoting safe walking and cycling to improve public health: Les-sons from the Netherlands and Germany. Am. J. Public Health 2003, 93, 1509-1516. [CrossRef] [PubMed]

3. Holleis, P.; Luther, M.; Broll, G.; Cao, H.; Koolwaaij, J.; Peddemors, A.; Ebben, P.; Wibbels, M.; Jacobs, K.; Raaphorst, S. TRIPZOOM: A system to motivate sustainable urban mobility. In Proceedings of the 1st International Conference on Smart Systems, Devices and Technologies, Stuttgart, Germany, 27 May-1 June 2012.

4. Fogg, B.J. Persuasive Technology: Using Computers to Change What We Think and Do; Morgan Kaufmann: San Francisco, CA, USA, 2003.

5. Kitchenham, B.A.; Charters, S. Procedures for Performing Systematic Literature Reviews in Software Engineering; EBSE Technical Report; Software Engineering Group, Keele University: Keele, UK; Department of Computer Science, University of Durham: Durham, UK, 2007.

6. Reitberger, W.; Ploderer, B.; Obermair, C.; Tscheligi, M. The PerCues Framework and Its Application for Sustainable Mobility. In Proceedings of the 2nd International Conference on Persuasive Technology, Palo Alto, CA, USA, 26-27 April 2007; pp. 92-95.

7. Froehlich, J.; Dillahunt, T.; Klasnja, P.; Mankoff, J.; Consolvo, S.; Harrison, B.; Landay, J.A. UbiGreen: Investigating a Mobile Tool for Tracking and Supporting Green Transportation Habits. In SIGCHI Conference on Human Factors in Computing Systems; ACM: New York, NY, USA, 2009; pp. 1043-1052.

8. Jariyasunant, J.; Abou-Zeid, M.; Carrel, A.; Ekambaram, V.; Gaker, D.; Sengupta, R.; Walker, J. Quantified Traveler: Travel Feedback Meets the Cloud to Change Behavior. J. Intell. Transp. Syst. 2013, 19, 109-124. [CrossRef]

9. Jylhä, A.; Nurmi, P.; Sirén, M.; Hemminki, S.; Jacucci, G. MatkaHupi: A Persuasive Mobile Application for Sustainable Mobility. In Proceedings of the 2013 ACM Conference on Pervasive and Ubiquitous Computing Adjunct Publication, Zurich, Switzerland, 8-12 September 2013.

10. Meloni, I.; Sanjust, B.; Delogu, G.; Sottile, E. Development of a technological platform for implementing VTBC programs. Transp. Res. Procedia 2014, 3, 129-138. [CrossRef]

11. Bothos, E.; Prost, S.; Schrammel, J.; Röderer, K.; Mentzas, G. Watch your Emissions: Persuasive Strategies and Choice Architecture for Sustainable Decisions in Urban Mobility. PsychNol. J. 2014, 12, 107-126.

12. Baird, T.; Zhao, J. 'Nudging' Active Travel: A Framework for Behavioral Interventions Using Mobile Technology. In Proceedings of the Transportation Research Board 93rd Annual Meeting, Washington, DC, USA, 12-16 January 2014.

13. Gabrielli, S.; Maimone, R. Digital Interventions for Sustainable Urban Mobility: A Pilot Study. In Proceedings of the 2013 ACM Conference on Pervasive and Ubiquitous Computing Adjunct Publication, Zurich, Switzerland, 8-12 September 2013. 
14. Kazhamiakin, R.; Marconi, A.; Perillo, M.; Pistore, M.; Valetto, G.; Piras, L.; Perri, N. Using Gamification to Incentivize Sustainable Urban Mobility. In Proceedings of the IEEE International Smart Cities Conference (ISC2), Guadalajara, Mexico, 25-28 October 2015; pp. 1-6.

15. Oinas-Kukkonen, H.; Harjumaa, M. A Systematic Framework for Designing and Evaluating Persuasive Systems. In Proceedings of the 3rd International Conference on Persuasive technology, Oulu, Finland, 4-6 June 2008; pp. 164-176.

16. Takayama, C.; Lehdonvirta, V.; Shiraishi, M.; Washio, Y.; Kimura, H.; Nakajima, T. Ecoisland: A system for persuading users to reduce $\mathrm{CO}_{2}$ emissions. In Software Technologies for Future Dependable Distributed Systems; IEEE: Tokyo, Japan, 2009; pp. 59-63.

17. Bliznyuk, A. Green Daily Guide. Easier environmentally friendly transportation with the help of mobile technologies. In Proceedings of the 2011 IEEE International Conference on Collaboration Technologies and Systems (CTS), Philadelphia, PA, USA, 23-27 May 2011.

18. Shankari, K.; Park, J.; Gadgil, T.; Katz, R.H.; Culler, D.E. Information Display for Societal Problems: Data, Game, or Choice? Technical Report No. UCB/EECS-2015-7; University of California at Berkeley: Berkeley, CA, USA, 2015.

19. Ebermann, C.; Brauer, B. The Role of Goal Frames Regarding the Impact of Gamified Persuasive Systems on Sustainable Mobility Behavior. In Proceedings of the 24th European Conference on Information Systems, İstanbul, Turkey, 12-15 June 2016.

20. Wunsch, M.; Millonig, A.; Seer, S.; Schechtner, K.; Stibe, A.; Chin, R.C. Challenged to bike: Assessing the potential impact of gamified cycling initiatives. In Proceedings of the Transportation Research Board 95th Annual Meeting, Washington, DC, USA, 10-14 January 2016.

21. Semanjski, I.; Lopez Aguirre, A.J.; De Mol, J.; Gautama, S. Policy 2.0 Platform for mobile sensing and incentivized targeted shifts in mobility behavior. Sensors 2016, 16, 1035. [CrossRef] [PubMed]

22. Khoshkangini, R.; Giuseppe, V.; Marconi, A. Generating Personalized Challenges to Enhance the Persuasive Power of Gamification. In Proceedings of the Second International Workshop on Personalization in Persuasive Technology Co-Located with the 12th International Conference on Persuasive Technology, Amsterdam, The Netherlands, 3-6 April 2017.

23. Schrammel, J.; Prost, S.; Mattheiss, E.; Bothos, E.; Tscheligi, M. Using Individual and Collaborative Challenges in Behavior Change Support Systems: Findings from a Two-Month Field Trial of a Trip Planner Application. In Proceedings of the International Conference on Persuasive Technology, Chicago, IL, USA, 4-5 June 2015; Springer: Cham, Switzerland, 2015; pp. 160-171.

24. Petri, M.; Pratelli, A.; Farina, A.; Buffi, A.; Franchina, V.; Nepa, P.; Christian, I. The SaveMyBike Project: ITS Technologies and Rewarding Policies to Improve Sustainable Mobility in Cities. In Proceedings of the Transportation Research Arena TRA, Vienna, Austria, 16-19 April 2018; pp. 1-10.

25. Cheng, Y.-M.; Chao-Lung, L. Persuasive and engaging design of a Smartphone App for cycle commuting. mUX J. Mobile User Exp. 2015, 4, 1-5. [CrossRef]

26. Park, H.; Sanguinetti, A.; Cortes, G.C. EcoTrips: Leveraging Co-benefits and Metaphorical Metrics in a Mobile App to Promote Walking and Biking for Short Trips. In Proceedings of the International Conference of Design, User Experience, and Usability, Vancouver, BC, Canada, 9-14 July 2017; Springer: Cham, Switzerland, 2017; pp. 60-76.

27. Myrovali, G.; Tsaples, G.; Morfoulaki, M.; Aifadopoulou, G.; Papathanasiou, J. An Interactive Learning Environment Based on System Dynamics Methodology for Sustainable Mobility Challenges Communication \& Citizens' Engagement. In Proceedings of the International Conference on Decision Support System Technology, Crete, Greece, 22-25 May 2018; Springer: Cham, Switzerland, 2018; pp. 88-99.

28. Anagnostopoulou, E.; Bothos, E.; Magoutas, B.; Schrammel, J.; Mentzas, G. Persuasive Interventions for Sustainable Travel Choices Leveraging Users' Personality and Mobility Type. In Proceedings of the International Conference on Persuasive Technology, Waterloo, ON, Canada, 16-19 April 2018; Springer: Cham, Switzerland, 2018; pp. 229-241.

29. Brazil, W.; Caulfield, B.; Bothos, E. An Examination of the Role of Emissions Information in Transport Behaviour: The Results of a Smart Phone Trial in Dublin, Ireland. In Proceedings of the 96th Annual Meeting of the Transportation Research Board, Washington, DC, USA, 8-12 January 2017. 
30. Harries, T.; Eslambolchilar, P.; Stride, C.; Rettie, R.; Walton, S. Walking in the wild-Using an always-on smartphone application to increase physical activity. In Proceedings of the IFIP Conference on Human-Computer Interaction, Cape Town, South Africa, 2-6 September 2013; Springer: Berlin/Heidelberg, Germany, 2013.

31. Bamberg, S. Applying the stage model of self-regulated behavioral change in a car use reduction intervention. J. Environ. Psychol. 2013, 33, 68-75. [CrossRef]

32. Mun, M.; Reddy, S.; Shilton, K.; Yau, N.; Burke, J.; Estrin, D.; Boda, P. PEIR, the personal environmental impact report, as a platform for participatory sensing systems research. In Proceedings of the 7th International Conference on Mobile Systems, Applications, and Services, Krakow, Poland, 22 June 2009; ACM: Wroclaw, Poland, 2009.

33. Gabrielli, S.; Maimone, R.; Forbes, P.; Masthoff, J.; Wells, S.; Primerano, L.; Pompa, M. Designing motivational features for sustainable urban mobility. In CHI'13 Extended Abstracts on Human Factors in Computing Systems; ACM: Paris, France, 2013.

34. Meurer, J.; Lawo, D.; Janßen, L.; Wulf, V. Designing mobility eco-feedback for elderly users. In Proceedings of the 2016 CHI Conference Extended Abstracts on Human Factors in Computing Systems, San Jose, CA, USA, 7-12 May 2016; ACM: New York, NY, USA, 2016.

35. Magliocchetti, D.; Gielow, M.; De Vigili, F.; Conti, G.; De Amicis, R. A personal mobility assistant based on ambient intelligence to promote sustainable travel choices. Procedia Comput. Sci. 2011, 5, 892-899. [CrossRef]

36. Sochor, J.L.; Strömberg, H.; Karlsson, M. Travelers' Motives for Adopting a New, Innovative Travel Service: Insights from the UbiGo Field Operational Test in Gothenburg, Sweden. In Proceedings of the 21st World Congress on Intelligent Transport Systems, Detroit, MI, USA, 7-11 September 2014.

37. Pangbourne, K.; Masthoff, J. Personalised Messaging for Voluntary Travel Behaviour Change: Interactions between Segmentation and Modal Messaging; Universities Transport Studies Group: Bristol, UK, 2016.

38. Wells, S. SUPERHUB: Towards Argumentatively Rich Persuasive Communication in Large-Scale, Applied Behaviour Change Systems; Extended abstract for Computational Models of Argument (COMMA) Demo Track; IOS Press: Scottish Highlands, UK, 2014.

39. Wells, S.; Pangbourne, K. Using Argumentation within Sustainable Transport Communication. In Argumentation and Reasoned Action, Proceedings of the 1st European Conference on Argumentation; College Publications: Lisbon, Portugal, 2015; Volume 1.

40. Castell, N.; Liu, H.; Kobernus, M.; Berre, A.J.; Noll, J.; Cagatay, E.; Gangdal, R. Mobile technologies and personalized environmental information for supporting sustainable mobility in Oslo: The Citi-Sense-MOB approach. In Proceedings of the 28th International Conference on Informatics for Environmental Protection, Oldenburg, Germany, 10-12 September 2014.

41. Wu, S.; Bai, Q.; Sengvong, S. Greencommute: An influence-aware persuasive recommendation approach for public-friendly commute options. J. Syst. Sci. Syst. Eng. 2018, 27, 250-264. [CrossRef]

42. Kelpin, R.; Flemming, G.; Heinrichs, M. Streetlife Field Trials-Applied Gamification Approaches as a Key to more Sustainable Mobility Behaviour. In Proceedings of the 44th European Transport Conference, Barcelona, Spain, 5-7 October 2016.

43. Huang, B.; Thomas, T.; Groenewolt, B.; Fioreze, T.; van Berkum, E. The Effect of Incentives to Promote Cycling: A Mobility Living Lab. In Proceedings of the Transportation Research Board 97th Annual Meeting, Washington, DC, USA, 7-11 January 2018.

44. Waygood, E.; Owen, D.; Avineri, E. Analytical or Emotional? Which stimulates greater sustainable travel intention. In Proceedings of the 92nd Annual Meeting of the Transportation Research Board, Washington, DC, USA, 13-17 January 2013.

45. Waygood, O.; Avineri, E. The effect of loss framing on the perceived difference of $\mathrm{CO}_{2}$ amounts: Implications for advanced travel information systems (ATIS). In Proceedings of the 43rd Universities Transport Study Group Conference, Milton Keynes, UK, 5-7 January 2011.

46. Avineri, E. Applying behavioural economics in the design of travel information systems. In Proceedings of the 43rd Universities Transport Study Group Conference, Milton Keynes, UK, 5-7 January 2011.

47. Avineri, E. User interpretation of travel information and implications for system design. In Proceedings of the 6th ACM Workshop on Next Generation Mobile Computing for Dynamic Personalised Travel Planning, Ambleside, UK, 25-29 June 2012.

48. Steg, L. Car Use: Lust and Must. Instrumental, Symbolic and Affective Motives for Car Use. Transp. Res. Part A Policy Pract. 2005, 39, 147-162. [CrossRef] 
49. Fielding, K.S.; Head, B.W. Determinants of Young Australians Environmental Actions: The Role of Responsibility Attributions, Locus of Control, Knowledge and Attitudes. Environ. Educ. Res. 2011, 18, 171-186. [CrossRef]

50. Worsley, A.; Skrzypiec, G. Environmental Attitudes of Senior Secondary School Students in South Australia. Glob. Environ. Chang. 1998, 8, 209-225. [CrossRef]

51. Schahn, J.; Damian, M.; Schurig, U.; Füchsle, C. Konstruktion und Evaluation der dritten Version des Skalensystems zur Erfassung des Umweltbewusstseins (SEU-3). Diagnostika 2000, 46, 84-96. [CrossRef]

52. Prochaska, J.O.; Velicer, W.F. The transtheoretical model of health behavior change. Am. J. Health Promot. 1997, 12, 38-48. [CrossRef] [PubMed]

53. Ajzen, I. Theory of planned behavior. Organ. Behav. Hum. Decis. Process. 2011, 50, 179-211. [CrossRef]

54. Heckhausen, H.; Gollwitzer, P.M. Thought contents and cognitive functioning in motivational versus volitional states of mind. Motiv. Emotion 1987, 11, 101-120. [CrossRef]

(C) 2018 by the authors. Licensee MDPI, Basel, Switzerland. This article is an open access article distributed under the terms and conditions of the Creative Commons Attribution (CC BY) license (http://creativecommons.org/licenses/by/4.0/). 